
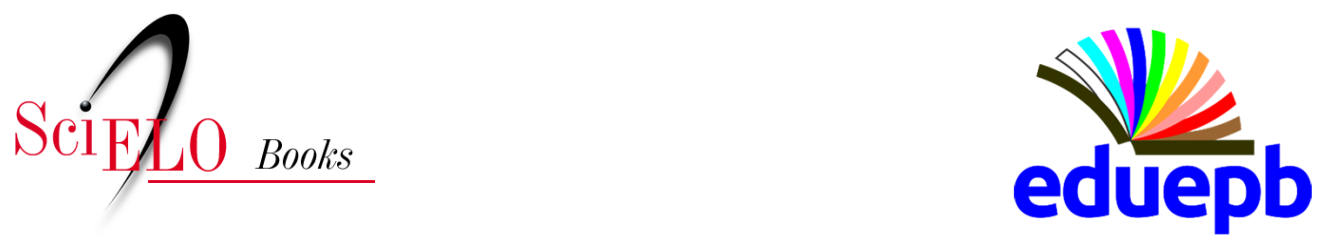

Parte II - Políticas, Escalas, Territórios

\title{
Para pensar as espacialidades e as temporalidades dos processos sociais regionalizados em conjuntura de crise disruptiva
}

\author{
Carlos Antônio Brandão
}

\section{SciELO Books / SciELO Livros / SciELO Libros}

BRANDÃO, C. A. Para pensar as espacialidades e as temporalidades dos processos sociais regionalizados em conjuntura de crise disruptiva. In: SOUSA, C. M., THEIS, I. M., and BARBOSA, J. L. A., eds. Celso Furtado: a esperança militante (Desafios): vol. 3 [online]. Campina Grande: EDUEPB, 2020, pp. 217-239. Projeto editorial 100 anos de Celso Furtado collection, vol. 3. ISBN: 978-65-86221-12-1. https://doi.org/10.7476/9786586221688.0009.

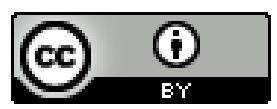

All the contents of this work, except where otherwise noted, is licensed under a Creative Commons Attribution 4.0 International license.

Todo o conteúdo deste trabalho, exceto quando houver ressalva, é publicado sob a licença Creative Commons Atribição 4.0.

Todo el contenido de esta obra, excepto donde se indique lo contrario, está bajo licencia de la licencia Creative Commons Reconocimento 4.0. 


\section{Para pensar as espacialidades e as temporalidades dos processos sociais regionalizados em conjuntura de crise disruptiva}

Carlos Antônio Brandão ${ }^{1}$

Toda decisão envolve uma forma de exercício de uma forma de poder". [Seria preciso] "identificar a natureza do sistema de dominação: seu relacionamento com a estratificação social, seus meios de legitimação, sua organização no espaço, seus meios de reprodução etc. (FURTADO, 1980, p. 33).

\section{Introdução}

Ceguindo as pistas de Stuart Hall e Doreen Massey (2010, P.

57), quando afirmam que "uma conjuntura é um período durante o qual diferentes contradições sociais, políticas, econômicas e ideológicas, que estão em ação, vêm se juntar em uma específica e distintiva forma”, procuramos pensar a presente condensação de contradições em 2020 e propor um conjunto de questões ligadas aos processos sociais regionalizados nesta conjuntura de crise disruptiva.

Há momentos históricos cruciais, em que a confluência de determinações e circunstâncias potenciais ou pendentes acabam se desenrolando em uma situação de rompimento abrupto da trajetória pregressa, engendrando um novo regime pósnormal. Ziauddin Sardar (2010), discutindo os tempos pósnormais, afirma que nesses contextos problemáticos, de incerteza e ignorância para a tomada de decisões políticas, seria preciso ter imaginação e criatividade na nova era marcada por complexidades, contradições e o caos.

1 Professor Titular do IPPUR/UFRJ. Doutor, Livre Docente e Professor Titular pelo Instituto de Economia da Unicamp. Pós-doutor pela Universidade British Columbia e pelo Centro de Estudos Sociais da Universidade de Coimbra. Bolsista do CNPq. Coordenador do site www.interpretesdobrasil.org. Coordenador do Observatório Celso Furtado para o Desenvolvimento Regional do Centro Internacional Celso Furtado. E-mail: brandaoufrj@gmail.com. 
Estamos perplexos diante da conjuntura de condensação de contradições, conflitos, caos e crise. Talvez precisemos de uma outra pedagogia da crise econômica, política e social, como propõem Bob Jessop e Karim Knio (2019). Eles buscam discutir a natureza e os horizontes espaço-temporais das crises vistas não como eventos acidentais ou excepcionais, anomalias ou distúrbios momentâneos, mas enquanto processos sistêmicos e multideterminados, em multifacetado mosaico, que desorientam e desestabilizam a sabedoria convencional e os contextos estruturais anteriores. $\mathrm{Na}$ conjuntura atual estamos atormentados por uma crise pandêmica e uma crise estrutural resultante do avanço neoliberal.

Melhor do que falar em era do neoliberalismo, seria caracterizar as últimas décadas como um processo de neoliberalização, que vai ocorrendo em distintas rodadas cíclicas: um processo dinâmico, plástico e resiliente, com repercussões variadas nos âmbitos sociais e espaciais e que lança mão de dispositivos, mecanismos e instrumentos bastante diferenciados de experimentações rerregulatórias pró-mercado e de mercantilização parametrizada. Imersos na mercadejação ou marquetização radical e na voracidade caótica da crise multidimensional contemporânea, não temos, no momento, forças acumuladas para o contraponto. O Estado, que poderia coordenar decisões transformadoras, foi "incapacitado para responder a emergências" (SOUSA SANTOS, 2020) e a sociedade parece perplexa, amorfa ou anestesiada. Pior, o processo de neoliberalização, metamorfoseando-se continuamente, sendo flexível e adaptando-se a cada tempo-espaço concreto, ingressa em uma conjuntura de pós-verdade, autocrática e pós-democrática novo-normal.

Mesmo nesta conjuntura desfavorável, poderia existir uma abertura para gerar fissuras e brechas a ocupar ou oportunidades emancipatórias a explorar? Talvez fosse o tempo de quebrar o senso comum de todos os fundamentalismos, inclusive o de mercado. Tempo de buscar engendrar outras condições de existência social, que não a econômica ou a individualista. Perseguir o enriquecimento cultural além do material, alargando os horizontes de possibilidades, segundo o conceito furtadiano. Recolher e enfeixar condições objetivas e subjetivas que lograssem se contrapor à constelação de injustiças que nos são impostas e nos constrangem, estruturando e legitimando decisões alternativas.

Como nos ensina Celso Furtado (1967), decisão pode ser vista, ora como uma unidade, um elemento ao longo de uma cadeia de decisões, ora como um centro de irradiação e de influência das decisões de outros agentes. Na primeira, como um elemento ao longo de uma cadeia, está-se 
colocando ênfase no fato de a decisão constituir, até certo ponto, resposta "passiva" a uma situação social posta; na segunda, como um núcleo de irradiação de decisões, põe-se o acento no fato de que uma decisão é capaz de modificar "ativamente" dada situação ou contexto social.

Neste contexto geral, elaboro neste ensaio exploratório alguns apontamentos acerca da necessidade da área do desenvolvimento regional avançar em uma teorização do papel fundante das decisões cruciais dos agentes dominantes e seus contrapoderes. Defendo a necessidade da realização de atividades de ensino, pesquisa e extensão que não negligenciem as estruturas constitutivas mais gerais, mas que, ao mesmo tempo, não percam as lógicas das conjunturas mais particulares. É essencial buscar apreender as estruturas constituintes das relações sociais em suas articulações com o todo, mas, simultaneamente, acompanhar os movimentos da conjuntura, os elementos contingenciais e circunstanciais das temporalidades mais curtas e das espacialidades mais imediatas.

O momento poderia ser de tomada de decisões com ousadia e inventividade. Ou seja, requereria decisões de outra natureza do que aquelas características do status-quo.

Defendo aqui que a questão regional hoje deveria se expressar, antes de tudo, na forma de decisões ousadas nucleadas na provisão de direitos e bens e serviços coletivos. Proponho a discussão de uma estratégia territorializada de um adequado padrão de oferta de bens, equipamentos e serviços públicos e coletivos para enfrentar a destituição de direitos e as desigualdades variadas nas escalas microrregional, supralocal e do lugar no Brasil.

Destaco que a escala regional apresenta virtualidades e potencialidades a serem melhor exploradas. Ao mesmo tempo, as escalas subregionais também não podem ser perdidas de perspectiva quando se pretende empreender lutas contra o desenvolvimento desigual e enfrentar decisivamente as destituições e as injustiças.

A escala regional só pode ser vista de forma relacional, em sua coerência estruturada, na posicionalidade de seu específico ambiente e no contexto histórico com suas particulares e específicas capacidades de decisão, relações de propriedade e poder etc., mas também em seus nexos, acionamentos e articulações interescalares no todo da divisão inter-regional do trabalho. Nas escalas subregionais, as práticas espaciais de sujeitos sociopolíticos em seus loci de pragmatismo, no acontecer do imediato e do vivenciado concretamente em cada espaço e cada conjuntura também requerem análise. 
Assim, avalio que as pesquisas e os cursos de pós-graduação em desenvolvimento regional deveriam continuar a mergulhar nas suas especificidades geográficas, históricas, estruturais e conjunturais dos seus respectivos mundos micro e mesorregionais, buscando captar toda a riqueza da diversidade e da complexidade de seus contextos e posicionalidades frente ao todo. Seus estudos bem situados, geográfica e historicamente, são fundamentais para suas singulares regiões e para o Brasil. Entretanto, não deveriam flertar com concepções teórico-metodológicas conservadoras, pois estas já demonstraram que não tem nada a ver com as nossas formações e realidades socioeconômicas, territoriais, culturais e espaciais.

\section{Os variados Cs: conjuntura complexa de condensação de contradições e conflitos na caótica crise}

Analisar nosso atual e desafiante tempo histórico como conjuntura, vista como um complexo processo de condensação de contradições, ajuda a arguir sobre as temporalidades e espacialidades desse momento radical de rupturas em que estamos agora mergulhados. Mais do que nunca, é indispensável buscar a imaginação e a criatividade nesta conjuntura atravessada por complexidades, contradições e o caos.

Entretanto, a conjuntura não é favorável a nenhuma ousadia. Desde o final dos anos 1970, ingressamos em um mundo parametrizado, normalizado, marquetizado e perplexamente dominado pelo mercado e pelo neoliberalismo (CAHILL et al., 2019; BERNDT et al., 2020). O acelerado e disruptivo tempo conjuntural em que estamos vivendo (que expressa inédita condensação do tempo estrutural) revela a tentativa radical (vencedora pelo menos na atual quadra histórica) de desestabelecer do mercado em relação às forças sociais. Trata-se de conjuntura de conexões contraditórias, no sentido de Doreen Massey e Stuart Hall, que parece confirmar a vitória do "moinho satânico" da mercantilização extrema, no sentido apontado por Karl Polanyi (1980). O processo de neoliberalização ingressa em uma fase de pós-verdade, autocrática e pós-democrática. Para complicar a crise econômica, política e social em que estamos mergulhados, temos também as crises ambiental, energética e sanitária irrompidas a partir da pandemia de 2020.

Nesta conjuntura adversa, somos convidados a ousar pensar com radicalidade e com especificidade, como diria Francisco de Oliveira (2001). 
Por um lado, é crucial buscar apreender as estruturas. Olhar para a totalidade do "orgânico", para a coerência estruturada, tentando capturar o conjunto das interconexões sociais, com suas racionalidades e regularidades e com os movimentos históricos de longa duração. Por outro, é preciso cultivar, em aproximações sucessivas, uma perspectiva teórica que lembra o que Doreen Massey chamou de procura por um enquadramento teórico metodológico mais flexível, capaz de apreender os movimentos, dinâmicas e mudanças. Ou seja, é necessário examinar minuciosamente os processos e as transformações estruturais, porém as estruturas devem ser analisados sem direção predeterminada.

Porém, ao mesmo tempo, torna-se necessário não negligenciar os movimentos da conjuntura, o "inorgânico", a conjunção e condensação de contingências, que engendram e põem em ação táticas e estratégias sociopolíticas circunstanciadas. São articulações mais imediatas, situadas e contingenciais, sujeitas a temporalidades mais curtas, possibilitando a coexistência conflitiva, contestada, relacional e contraditória do real-concreto mais imediato e mundano.

Essa adequada e melhor percepção dos movimentos dos espaços e tempos estruturais e conjunturais pode nos auxiliar na interpretação dos específicos processos socioespaciais, que devem ser analisados em seu movimento histórico, contraditório e dinâmico. Devem, também, percorrer teórica e empiricamente as interconexões entre práticas conjunturais e as estruturas, observando as variadas escalas desses processos de combinação das formas variadas existentes, neste momento em que a América Latina e o mundo passam por transformações radicalizadas.

Infelizmente, vivemos, mais uma vez, uma daquelas rodadas do predomínio dos modelos importados para pensar concretamente nossa realidade. Há clara colonização do pensamento e perda de criatividade intelectual para refletir a partir de uma perspectiva de conjunto. A fragmentação do campo de conhecimento territorial-espacial, a hegemonia dos paradigmas conservadores, os desvios promovidos pelo debate da "pós-modernidade" e sua proposta de "derrocada das grandes narrativas", o avanço da razão neoliberal, dentre outros fatores, têm dificultado o avanço para trajetórias mais substantivas de entendimento da realidade concreta em sua dinâmica contraditória de transformação.

Há pouco espaço teórico para as análises sustentadas na dinâmica das relações sociais contraditórias. Predomina uma perspectiva de harmonia social em parte das pesquisas da área. Não há espaço para a oposição ou interdependência dos agentes e suas práticas. Elabora-se um discurso 
sofisticado de estabilização social, sem a discussão das bases materiais, como se houvessem práticas (harmoniosas) sem estruturas (em movimento contraditório e tenso). De análises que tinham uma concepção de estruturas sem sujeitos, corremos o risco de termos caído em representações de atores sem estruturas.

Como a dimensão espacial em si já é interface de múltiplas dimensões, é certo que nenhum campo disciplinar isoladamente dará conta da riqueza de determinações deste complexo processo. Entretanto, apesar do discurso sofisticado sobre trans-, multi- e inter-disciplinaridade, pouco respeito há entre os campos disciplinares e muito menos sua devida articulação para estruturar objetos de conhecimento relevantes e pertinentes.

Para se ter uma visão melhor determinada, mediada e qualificada sobre o espaço, que possam apresentar potencial de apreensão e transformação teórica e política de nossa realidade. Amplas potencialidades se encontram disponíveis hoje de reconstrução teórico-metodológica crítica, que poderiam informar e estruturar disputas políticas em torno das ações sociais no ambiente construído, informando movimentos contestatórios e/ou a orientação de políticas públicas democráticas.

Se concebermos o desenvolvimento como um processo complexo de decisões que logram estruturar o pleno exercício de opções alternativas que alargam os horizontes civilizatórios, inexoravelmente construídas em tensão sociopolítica, então ele é só trajetórias abertas, sujeitas ao embate estratégico em contexto de incontornável diferenciação de poder (de comando sobre o destino de determinada sociedade). Assim, desenvolvimento é distorcer a correlação de forças, importunar diuturnamente as estruturas e coalizões tradicionais de dominação e reprodução do poder. É exercer em todas as arenas políticas e esferas de poder uma pressão tão potente quanto o é a pressão das forças sociais que perenizam o subdesenvolvimento. Neste sentido, carecemos de melhor identificação e qualificação dos limites e das potencialidades de construção de estratégias de desenvolvimento que possam avançar maiores níveis de integração e coesão social, físico-territorial e econômica do país nos próximos anos, valorizando o trunfo de nossa diversidade e criatividade, enfrentado o encadeamento das ações de veto dos projetos hegemônicos que buscam perenizar o atraso e a falta de democracia.

Celso Furtado (1967, p. 92) bem sintetizou que

o estudo do desenvolvimento tende a concentrar-se na caracterização das estruturas, na identificação dos agentes significativos e nas interações entre determinadas 
categorias de decisões e as estruturas. Estas condicionam o processo de irradiação e a eficácia no espaço e no tempo das decisões, mas ao mesmo tempo são por elas determinados.

Albert Hirschman identificou nas situações do subdesenvolvimento da "falta de capacidade para tomar decisões". Nestes contextos, seria necessário, segundo Sunkel e Paz (1971, p. 38), elaborar "uma estratégia de desenvolvimento desequilibrada para forçar decisões que, de outro modo, não seriam tomadas".

Inspirado por estas concepções críticas latino-americanas, seria importante avançar em estudos regionais que lograssem depurar, discriminar e hierarquizar os fatores endógenos e exógenos determinantes, condicionantes ou coadjuvantes dos processos sociais, econômicos, políticos etc. em cada território sob análise. Esses estudos devem procurar construir mediações históricas, teóricas (e por que não dizer institucionais, territoriais, políticas etc.) devidas e pertinentes, cultivando para se uma abordagem teórica e metodológica da produção social do espaço, dos conflitos que se estruturam e das lutas (das frações de classe e das facções sociais) que se travam e tramam em torno deste ambiente construído.

Dever-se-ia ter sempre presente que o espaço é uma unidade dinâmica de reprodução social, por ser encarnação de processos e projetos diversos e manifestação concreta de conflitualidades de projetos políticos em disputa. Seu tratamento, portanto, requer o abandono dos tratamentos tecnicistas que pensam estruturas sem decisões de sujeitos reais ou atores atomizados sem contexto estrutural. Os espaços são construções (sociais, discursivas e materiais) e sua análise exige que nos baseemos na interação entre decisões e estruturas, nas articulações entre microprocessos, microiniciativas versus macrodecisões, nas múltiplas escalas espaciais e nas várias conjunturas em que se organizam e se enfrentam os interesses em cena e em disputa.

Proponho aqui que o refinamento analítico requerido passa pela centralidade das decisões e do poder de comando de sujeitos concretos, situados e envolvidos nas disputas diversas (com variados instrumentos) em torno da construção social de determinado espaço, investigando as hierarquias e hegemonias de poder de comando, as ações e as cadeias de reações das decisões tomadas (por variados agentes e sujeitos sociais que operam em variadas escalas espaciais). 


\section{Decisões cruciais de agentes dominantes com poder, envoltos em estruturas-conjunturas geohistóricas e contextos sociopolíticos específicos}

Procuro desenvolver aqui uma argumentação que defende que os estudos regionais deveriam colocar no centro de suas metodologias a análise do sistema decisional (público e privado) e seus poderes.

Coloco no centro desta abordagem metodológica a problemática das decisões concebidas como elemento de uma cadeia de ações e reações de algumas unidades de poder com recursos assimétricos e capazes de comando e dominação.

Entendo que a constituição e o exercício concreto de poder de comando de agentes e sujeitos reais, que operam em variadas escalas espaciais, nas disputas em torno da produção social de determinado espaço precisam ser investigadas detalhadamente.

Como já afirmava Max Weber (1922), os processos de desenvolvimento econômico são lutas de dominação. O desenvolvimento desigual, envolvendo processos de dominação e irreversibilidades diferenciais, impõe hierarquias, relações de força assimetricamente constituídas e exercidas por variados veículos e escaninhos de poder. Há a imposição de hierarquias, relações de força desigualmente constituídas e exercidas. São erguidas estruturas com complexidade díspar, com potência assimétrica e heterogênea, configurando lógicas hierarquizadas. A discussão destes processos e forças desemboca na questão terminal do poder diferencial de capacidade de decisão, fruto de uma correlação de forças que está sintetizada no processo de hegemonia. Como processo síntese, o poder de comando, de dominação de classe, é exercido e legitimado tendo por base determinada equação política, que se configura em um arco de alianças, um pacto de poder, assentado em certa correlação de forças políticas, que dá direção e domínio das condições sociais em determinado território.

Celso Furtado afirmava que

os processos sociais tendem a apresentar-se sob a forma de reações causais em cadeia, ou seja, cumulativamente (...) Analisando as cadeias de reações provocadas por decisões autônomas, será possível identificar fatores que aumentam ou reduzem sua capacidade de decisão (FURTADO, 1967, p. 90).

A capacidade promissora de uma metodologia que possa investigar a força motora de uma decisão, sua capacidade de propagação e de gerar 
tensão nas estruturas deveria estar no centro de uma abordagem que possa orientar, direcionar e reordenar processos complexos.

Incluem-se aí processos como aqueles atinentes à produção social do espaço e às outras formas de conceber estratégias regionais que possam acumular capacidade de decisão para a transformação política. Mudança que alargue os horizontes de decisões e de possibilidades, que seria o verdadeiro desenvolvimento,

que é principalmente um processo de ativação e canalização de forças sociais, de avanço na capacidade associativa, de exercício da iniciativa e da inventiva. Portanto, se trata de um processo social e cultural, e só secundariamente econômico (FURTADO, 1982, p. 149).

Ou seja, produz-se o desenvolvimento com intencionalidade, pois "o desenvolvimento significa a gênese de formas sociais efetivamente novas”.

A experimentação teórico-metodológica proposta aqui busca colocar no centro da análise a problemática das decisões. O refinamento analítico e categorial requerido passa pela centralidade das decisões e do poder de comando de sujeitos concretos, situados e envolvidos nas disputas diversas (com variados instrumentos) em torno da construção social de determinado espaço, investigando as hierarquias (divisão social do trabalho) e hegemonias de poder de comando.

É preciso conferir atenção às ações e às cadeias de reação das decisões tomadas por agentes e sujeitos sociais que se situam e operam em variadas escalas espaciais e que se encontram em interação. Essa interação entre atores, agentes e sujeitos forja e transforma estruturas, estratégias e determinados campos espaciais e arenas de luta e de conflituosidade.

É imperioso concentrar atenção na análise dos agentes cruciais e seus efeitos de dominação, examinar as estruturas decisórias e a natureza da atuação dos agentes, procurando entender como vão se redefinindo, no processo histórico e conjuntural, o modo de ação e o relacionamento entre os heterogêneos espaços urbano-regionais.

É preciso elaborar instrumentos analíticos de uma economia política da manifestação dos processos sociais no espaço, problematizando estruturas e sujeitos produtores dos espaços, elegendo as problemáticas do poder e dos processos decisórios dos agentes dominantes (Estado e grande empresa) como as nucleares para a análise e a ação consequentes e comprometidas com a justiça socioespacial.

Neste contexto, os estudos urbano-regionais devem assumir a conflitualidade inerente e a contenda perene de interesses múltiplos e seus 
variados loci de possibilidade de concertação, ou não, de projetos em disputa e das coalizões e arco de alianças que vão se armando em cada conjuntura histórica e territorial.

A assunção da conflitualidade, a dinâmica de ação das facções das classes sociais e a identificação dos sujeitos sociopolíticos portadores de decisão transformadora devem ser uma constante nos estudos regionais.

Se a reprodução social da vida necessita ocupar papel central na análise, por outro lado, os atores, agentes e sujeitos não são autômatos (ou unidades atomísticas racionais) que obedecem imediatamente leis gerais de movimento que lhes determinem suas ações.

Ação dotada de sentido, finalidade e intencionalidade tem

um movimento que necessariamente se realiza através de sujeitos, individuais e/ou coletivos, que, ao agirem, desencadeiam séries causais. As formas espaciais produzidas pela sociedade manifestam projetos, interesses, necessidades, utopias. A práxis humana é alimentada por pré-ideações que têm o espaço vivenciado como estímulo (MORAES, 2002, p. 22).

Discutindo a posição de Marx nesta questão, Sereni (1973, p. 63) afirma que este atribui ações a "agentes que não são apenas econômicos e estruturais, senão também superestruturais. É precisamente da multiplicidade e entrecruzamento de agentes e ações, internos e externos, de onde se faz derivar a não unilinearidade da sucessão de formações sociais ou da evolução de suas instituições, em relação às quais, portanto, ficam abertas diversas alternativas".

As análises concretas requerem a investigação criteriosa dos interesses (não só das identidades!) regionais, a concentração no estudo das estruturas espaciais, escalares e políticas, da estruturação do place, do habitat, da vida cotidiana, e dos projetos e das práticas dos sujeitos, tanto dos sujeitos constituídos e em constituição, quanto dos a constituir, articulando contextos e lógicas situadas, hierárquica e espacialmente, e ações.

Pierre Bourdieu, em "O singular e o plural", sustenta que:

As lógicas das práticas inscritas na história e no tempo são imanentes às práticas porque estas são ações, e não comportamentos (...) Suas determinações devem ser consideradas como estritamente sociais, por serem contestadas e insistentes, inteiramente imanentes às situações. [Nada nos pode] desviar de uma interrogação sobre as práticas compreendidas como ações, ou seja, como atos intencionais, inscritos na temporalidade para agir sobre o mundo (BOURDIEU, 2005, p. 152). 
Estes e outros autores nos proporcionam importantes insights sobre a centralidade das decisões, da premência em se analisarem os resultados e as consequências das decisões tomadas por agentes e sujeitos com poder heterogêneo e assimétrico.

Precisamos analisar as decisões cruciais, e questionar em quais atores, agentes e sujeitos se apoiam e qual o estatuto decisional destes. Alcouffe (2009), citando Furtado, fala da premência em se construir uma nova coerência teórica que leve em conta a desigualdade dos agentes, mas sublinhando a força da organização que a dominação traz. Bourdieu (1998) nos fala das cadeias de autoridade que expressam as articulações de força que se estruturam na sociedade.

É fundante "analisar a noção de poder e suas relações com a de espaço e delinear um marco teórico-interpretativo que aborde o acionar dos sujeitos sociais" (GARCÍA; ROFMAN, 2013, p. 103). Esses autores buscam uma análise da espacialidade do poder e realizam uma arguta sistematização dos principais autores desta temática (Claval, Rafestin, Massey, dentre outros), que entendem por poder tanto a capacidade de atuar como de fazer com que outros atuem, demonstrando a capacidade diferencial de dominação das diversas geometrias de poder temporalmente variáveis.

Relações sociais apresentam sempre vinculações espaciais e temporais, envolvendo alguma forma de controle de recursos materiais e simbólicos (GARCÍA; ROFMAN, 2013). Todas as relações sociais apresentam alguma dimensão ou são relações de dominação, condicionando de algum modo práticas de outros.

Já em 1974, Alejandro Rofman havia apresentado importante contribuição ao discutir os efeitos espaciais gerados pela ação dos tomadores de decisão no sistema capitalista dependente periférico. Defendeu a necessidade de se analisar simultaneamente

\begin{abstract}
a identificação dos agentes decisionais que operam no marco do poder econômico e político de cada uma das formações sociais e o efeito espacial gerado pelos agentes que se concretiza em uma específica estrutura urbano-regional em cada sistema social estudado (ROFMAN, 1974, p. 42).
\end{abstract}

Quanto aos agentes dominantes, é preciso distinguir a tomada de decisão pública da tomada de decisão privada. Examinar minuciosamente a tomada de decisão privada da classe proprietária, que tem poder de definir as unidades de decisão que operacionalizam o funcionamento econômico, com destaque para as decisões sobre o processo de inversão 
de capital. Esquadriar os instrumentos e as formas do exercício do poder estatal, posto que

a ação do Estado é configurada como um processo ininterrupto de decisões (...) no particular e de acordo com cada conjuntura histórica e é a resultante da luta de interesses setoriais do bloco dominante que se desenvolve em seu seio (ROFMAN, 1974, p. 27).

A capacidade de transformação do espaço social é desproporcionalmente realizada pelas classes proprietárias, por um lado. Por outro, o Estado, enquanto condensação de uma relação de forças também desempenha papel fundamental, também detém poder assimétrico de produção do meio ambiente construído.

Analisar o papel do Estado, dos grupos empresariais e corporações deve estar no centro dos estudos regionais. A análise da lógica e dos interesses ao longo das cadeias de decisões e reações a decisões tomadas pelo "mundo privado" é essencial, pois

\begin{abstract}
as decisões empresariais sobre compra, venda, desenvolvimento de ativos e estratégias competitivas desempenham, todas elas, papéis num cenário geográfico" (...) "Por que é importante estudar o comportamento das empresas nas economias regionais? As decisões empresariais conformam tanto a distribuição inter-regionais da atividade econômica quanto a qualidade e natureza do trabalho dentro das regiôes" (MARKUSEN, 2005, p. 64).
\end{abstract}

Assim, o estudo pormenorizado, em cada espaço-tempo, dos projetos hegemônicos, segundo Jessop (2007), torna-se central a fim de se analisar os compromissos instáveis, as estruturas, forças e estratégias políticas e ideológicas que dão forma ao Estado e suas bases sociais de apoio e oposição. Os projetos hegemônicos buscam angariar o apoio das forças sociais relevantes, pelo menos momentaneamente, em cada conjuntura histórica (JESSOP, 2007).

Em síntese, os processos de estruturação do espaço apresentam conflitos de interesses entre agentes e sujeitos que forjam e transformam estruturas, estratégias e campos e arenas de luta e de conflitualidade entre projetos sociopolíticos distintos. Assim, o resgate da problemática da reprodução das classes sociais, das estruturas e das decisões, tornase questão inarredável para se entender a produção social do espaço e a dimensão urbano-regional do processo de desenvolvimento capitalista em cada contexto escalar específico. 
Além de investigar qual o poder do poder público, qual o poder do poder privado, é também fundamental examinar qual o poder das forças contra-hegemônicas. Contra toda sorte de espoliações socioterritoriais que as forças privadas promovem (que na maior parte das vezes induzem ou se legitimam nas forças estatais), é preciso que analisemos também as contra-re-ações das forças emancipatórias e reivindicativas, que buscam se contrapor às diversas modalidades de injustiças sociais e espaciais.

\section{Prover um adequado padrão de oferta de bens, serviços e equipamentos coletivos para enfrentar a destituição de direitos e as desigualdades nas escalas meso e microrregionais, supralocais e do lugar da vida cotidiana no Brasil}

Defendo aqui que as estratégias territorializadas de desenvolvimento deveriam estar orientadas por uma visão abrangente de um sistema de provisão de bens, infraestruturas, serviços e equipamentos coletivos de utilidade pública, sobretudo, nos espaços regionais mais carentes e desiguais.

Em países enormes, desiguais e heterogêneos como o Brasil é crucial promover o suporte infraestrutural da provisão de bens e serviços públicos essenciais e de uso coletivo para a consolidação de uma sociedade de direitos de massas, que busque ofertar de forma adequada, e a mais espraiada territorialmente possível, o acesso aos direitos sociais da reprodução cidadã (acesso à saúde, educação, seguridade social, transporte urbano de alta densidade, moradia, saneamento, ensino-aprendizagem etc.).

O desafio de transformar pelo imenso território o padrão de oferta de bens e serviços e a provisão de infraestruturas de utilidade pública e inovativas é tarefa hercúlea. A ação pública deveria, em uma nova geometria de poder, executar estratégias coletivas no sítio-lugar, instilando no espaço-tempo da (con)vivência cotidiana, uma cultura permanente de transformação pedagógica e politizante no sentido de crescente autoconsciência de seus direitos.

É necessário promover políticas redistributivas (não apenas focalizadas e compensatórias), que tenham capacidade de engendrar assimetrias virtuosas, de forma difusa e pervasiva, geradoras de combates frontais às heterogeneidades estruturais e aos variados e recalcitrantes lógicas e mecanismos socioeconômicos, culturais e políticos de destituição, exploração e marginalização. 
O Estado, em sua ação espacial (um Estado espacializado!), deve provocar, enfeixar, congregar e dar impulso a ações concretas que busquem o abandono de atitudes acomodatícias e alienantes por parte da população local-regional. Com isso, é possível construir uma verdadeira cidadania regionalista, ou melhor, um regionalismo cidadão, que promova e institucionalize o envolvimento, o diálogo e a concertação contratualizada de interesses, a fim de criar elementos políticos redutores de incertezas e neutralizadores de fatores de instabilidade, oportunismos e ciclos políticos. E, além disso, capazes de engendrar novos instrumentos de geração de escolhas públicas e coletivas para a solução de problemas específicos, impulsionando a criatividade social, com aderência, plasticidade e pragmatismo com lugares específicos.

Estas ações espaciais do Estado devem apoiar segmentos prioritários de grande capilaridade espacial ligados aos complexos de saúde e educação, habitação, saneamento, transporte urbano, recursos hídricos, energias renováveis, agricultura e processos produtivos de baixa intensidade de uso de recursos naturais e energia. Este Estado espacial tem a tarefa, premente nos países periféricos, de realizar redobrado esforço de inversão em serviços públicos de natureza social e coletiva, de utilidade pública, isto é, em Capital Básico Social e em atividades indiretamente produtivas. Ele deve fomentar tecnologias sociais que atendam demandas dos setores sociais mais necessitados, especialmente em temas como segurança alimentar e nutricional, energia, habitação, saúde, saneamento, meio ambiente, agricultura familiar, geração de emprego e renda, inserção de jovens.

Assim, é decisivo identificar e qualificar os limites e as potencialidades de construção de estratégias de desenvolvimento que possam avançar maiores níveis de integração e coesão social, físico-territorial e econômica do país nos próximos anos, valorizando o trunfo de nossa diversidade e criatividade e a complexidade do nosso processo de urbanização.

É urgente transformar profundamente o padrão de oferta de bens e serviços e de provisão de infraestruturas sociais de utilidade pública, sobretudo em seu segmento infraestrutura social e urbana (saneamento, habitação, metrôs, trens urbanos, universalização da eletricidade e pleno acesso aos recursos hídricos). Dever-se-ia, com grande diálogo e coordenação de políticas públicas, avançar na consistência e articulação das múltiplas interfaces dos variados sistemas: o Sistema Nacional de Fomento (BNDES, Caixa Econômica Federal, Banco do Brasil, Banco do Nordeste do Brasil etc.), o Sistema de Proteção e Provisão de Bem-Estar 
Social, o Sistema de Aprendizado/Educação/CTI e o Sistema Nacional de Políticas Urbanas, Rurais e Regionais.

O certo é que a mudança no Padrão de Oferta de Bens e Serviços tem potencialmente a possibilidade de reforçar os efeitos dinâmicos e sinérgicos entre estes sistemas (alguns deles ainda precários em sua estruturação). Como simples exemplos, dentre muitos outros de caráter sistêmico que poderiam ser lembrados: existia a possibilidade de se articular melhor as políticas de CTI e industriais em torno de equipamentos de água, mobilidade urbana de massa, saúde, lazer e cultura; era para ter se dado maior impulso às ações educativas, artísticas, de prevenção de doenças, pedagógicas-politizadoras; elas requereriam melhor articulação, através de postos e pontos de atendimento, eventos, utilização de espaços físicos como escolas, arenas e estádios de futebol, rádios comunitárias, emissoras públicas, clubes etc., em uma ação pública de indução massiva, catalisadora e integrada no terreno da vida cotidiana, a começar pelas áreas mais carentes dos espaços urbanos e rurais de cada região brasileira. $\mathrm{Na}$ verdade, esses exemplos e outros visam demonstrar que não deveria haver contradição, mas antes complementaridade, entre ações exigentes de tecnologias avançadas e de ponta e ações que reclamam antes tecnologias sociais e mobilização, ativismo e agitação sociocultural.

Propõe-se aqui formas emergenciais, um verdadeiro "tratamento de choque" na provisão de direitos, com adequadas quantidade e qualidade, que promovam a habilitação cidadã, com base na oferta incisiva, concentrada e enfeixada de bens e serviços de utilidade pública, enquanto meios de reprodução da vida social; e infraestruturas sociais e meios de consumo-direitos coletivos, ou seja, instrumentos auxiliares na formação ampliada das forças e capacidades produtivas e criativas-emancipatórias humanas, que possam desatar e mobilizar ações universalizantes e de criação de patamar adequado de homogeneidade social, pela via da construção da habilitação e das inovações sociais e institucionais. As ações de indução pública e coletiva precisam ultrapassar a simples lógica fragmentária, "setorialista" e compartimentada, promovendo a capacidade articuladora do tecido sócio-produtivo-territorial, ao lado de impulsionar os adequados engate e conexão de aparelhos produtivos localizados e a distribuição de riqueza e renda, habilitando e distribuindo territorialmente direitos sociais aos cidadãos. Essa ação de conjunto do Estado brasileiro deveria partir de uma visão de "não inventar a roda" (não propor, de início, nem novas políticas públicas, nem novas instituições), mas partir do que já se tem disponível (alguns ativos, capacitações e recursos ociosos ou 
latentes) em cada território: equipamentos, ações e iniciativas já existentes, identificação de lideranças, agentes de transformação e novas lógicas de participação. Seria importante utilizar institucionalidades já disponíveis, capacitando-as para a nova tarefa, por exemplo, os CRAS - Centro de Referência da Assistência Social. Antes de tudo, cabe construir um "efeito demonstração" da presença robusta e benfazeja do Estado no território. A população precisa sentir "de que lado estão os aparelhos estatais".

Em suma, é urgente prover o suporte adequado de bens e serviços públicos básicos, essenciais e coletivos, transformando o formato e as modalidades de chegada (com solidez, estabilidade e consistência) do Estado no território, com plasticidade e resiliência, no chão das práticas cotidianas e do imediato sensível, das experiências localizadas, no lócus específico de reprodução social das "pessoas de carne e osso". Urge realizar a provisão desses bens e serviços para a consolidação de uma sociedade de consumo e de direitos de massa, que logre acessar (territorialmente) plenamente direitos sociais e cidadania (saúde, educação, seguridade social, transporte urbano de alta densidade, moradia, saneamento, etc.). Do mesmo modo, é fundamental prover infraestruturas sociais que aperfeiçoem habilidades e propiciem habilitações. É preciso construir a atuação com alta efetividade do Estado brasileiro, por meio de institucionalidades, instrumentos e mecanismos que, capilarmente, difundam, concretizem e enraízem suas ações em todo o vasto território nacional.

O travamento da oferta e o não acesso à educação, propriedade e serviços públicos de qualidade destitui a maior parte da população brasileira dos direitos fundamentais da vida cidadã. Uma provisão com qualidade, que instale a habilitação cidadã deveria ter por base os serviços de utilidade pública enquanto meios de reprodução, de consumo coletivo, ou seja, instrumentos auxiliares na formação ampliada das forças e capacidades produtivas e inovativas humanas, que promovessem ações universalizantes e de criação de patamar adequado de homogeneidade social, pela via da construção de habilitação e das inovações sociais e institucionais.

O esforço de grande transformação da situação socioespacial brasileira deve ser articulado simultaneamente em variadas dimensões (tecnológica, produtiva, social etc.), em várias escalas espaciais (no lugar, na micro, meso e macro região, e nos espaços nacional, continental e internacional), coordenando diferentes níveis de governo (união, estados e municípios) e tendo por base múltiplas institucionalidades e diversificados sujeitos sociopolíticos. 
Deve-se pretender, com tais políticas, a "recomposição territorial" através da ação planejada, a reconstrução de espaços públicos e dos canais institucionalizados de participação e a criação de variadas arenas que possam aglutinar e dar vazão aos diferentes interesses.

Em suma, o Brasil necessita construir estratégias e instituições capazes de conectar os canais de interação entre crescimento econômico, integração territorial, construção de cidadania social, ciência, tecnologia e inovação e aprimoramento de capacidades humanas emancipadoras. Obviamente, estas estratégias ficam para um momento democrático de reconstrução do país, mas podem ir sendo implementadas de baixo para cima nas escalas locais e regionais.

\section{Restabelecer outros Ps: o poder participativo do povo. Cadeias de reação a decisões hegemônicas e luta pela democracia}

Desde o início do século XXI, um importante debate está em andamento sobre o momento pós-democrático, autoritário, autocrático e de pós-verdade. O processo de neoliberalização parece ter se consolidado de forma definitiva e brutal. Os seus métodos para fazer avançar as lógicas da mercantilização extremada, reposicionando de poder, já não importam.

A partir de 2020, tudo indica que os desdobramentos estruturais e conjunturais do regime pós-normal da pandemia do coronavírus poderão, por contraditório que possa parecer, acelerar, desatar e exacerbar diversas tendências que vinham se desenhando e confirmando de aumento desregrado da concentração e centralização da renda, da riqueza, da propriedade privada e do poder em todas as escalas espaciais, em grande parte, passando ao largo dos direitos individuais e coletivos e das regras democráticas.

O termo pós-democracia foi cunhado por Jacques Rancière (NASH, 1996) e desenvolvido e disseminado através do trabalho de Colin Crouch (2004). Esses autores mostram como os poderosos interesses das minorias se tornaram mais ativos e as elites políticas aprenderam a gerenciar e manipular cada conjuntura, multiplicando cada vez mais o poder de seus negócios e combatendo quaisquer alternativas para a redistribuição de poder e riqueza. Jessop (2019) fala de uma nova ordem, com a consolidação do neoliberalismo autoritário e seu regime de acumulação inevitavelmente propenso a crises, predatório e dominado pelas finanças e sua associação com um estado de austeridade duradoura, como um estado 
conjuntural de emergência ou um novo normal, realizado continuamente de maneira não democrática. Na América Latina, com sua longa tradição de ciclos autoritários e ditatoriais, o debate sobre pós-democracia pode oferecer um terreno fértil para a pesquisa de suas formas concretas.

Neste ambiente inóspito para o avanço das forças progressistas e da promoção de estratégias de combate às desigualdades e destituições, seria fundamental discutir e levar à frente formas de ampliar as decisões e torná-las mais permeáveis à ampla participação democrática, alargando e aperfeiçoando renovadas formas de controle do exercício de poder. Será preciso desafiar a imaginação para engendrar uma nova formação sociopolítica geohistórica, abrindo para o desenvolvimento de um novo cidadão sujeito e agente do processo decisório.

É necessário uma nova gramática, uma nova pedagogia e uma nova ontologia, a fim de promover o "exercício real da capacidade consciente de optar e escolher por finalidade e caminhos" (...) "Só o ser social pode ser assim livre" (MONTAÑO; DURIGUETTO, 2013, p. 8o). Ou seguindo Boaventura de Sousa Santos,

\begin{abstract}
Como as democracias são cada vez mais vulneráveis às fake news, teremos que imaginar soluções democráticas baseadas na democracia participativa a nível de bairros e comunidades, e na educação cidadã orientada à solidariedade e à cooperação, e não ao empreendedorismo e à competitividade a todo custo" (...) "A política, que deveria mediar as ideologias e as necessidades e aspirações dos cidadãos, tem renunciado a esta função. (SOUSA SANTOS, 2020, p. 25)
\end{abstract}

Estudos bem contextualizados e comparativos das mudanças estruturais-conjunturais dos variados espaços regionais são sempre muito bem-vindos neste contexto, buscando analisar as hierarquias das decisões informadas por sua posição de classe social. Seria necessário, neste contexto, investigar os contornos histórico-institucionais concretos em que se processam as ações sociais e as decisões de sujeitos e agentes de transformação.

Por exemplo, na escala regional, que pode ser desdobrada em outros sub-recortes, é possível elucidar as articulações das estruturas e dinâmicas mais localizadas com os outros níveis escalares, se constituindo em fundamental plano intermediário de observação.

Esta escala possui geralmente alguma autoridade e força política, controlando alguma base tributária e influenciando ou regulando algumas decisões extra-regionais. Deve aglutinar forças, articular a complementaridade produtiva e a solidariedade de interesses cruciais, e desenvolver 
capacidade mínima de modular sua inserção externa segundo sua posição relativa em uma divisão inter-regional do trabalho.

É crucial nas ações regionalizadas ter um Estado legitimado, potencializado e capacitado para tomar decisões que transformem a realidade, sobretudo, naqueles territórios mais destituídos de direitos, riqueza e poder, ter um Estado democrático que promova e amplie o poder participativo do povo. É preciso que haja pressão de baixo para cima para potencializar cadeias de reação a decisões hegemônicas e aglutinar forças para novas impulsões à radicalização da democracia.

Assim, requer-se ter presente nas pesquisas regionais a dinâmica de ação das diferenciadas facções das classes sociais, analisando a precária constituição de sujeitos sociopolíticos desalienados e portadores de decisões transformadoras. Essa precariedade coloca impasses estruturais à constituição de processos de desenvolvimento duradouros, inclusive em sua dimensão territorial.

Neste contexto inóspito, um olhar plural para as escalas subregionais e mesmo nas microescalas espaciais é fundamental. Como Massey e Rustin bem apontam:

É preciso haver respeito pela diversidade, pelas especificidades de cada esfera da vida e reconhecimento do que deveriam ser concepções orientadoras fundamentais de justiça, igualdade e 'democracia profunda'. A tarefa seria criar e sustentar um novo consenso em torno desses valores. (MASSEY: RUSTIN, 2015, p. 220)

Até por isso, é importante dimensionar o poder das facções subalternas nas lutas reivindicatórias de mobilização, protesto e de resistência, avaliando a real capacidade das forças contestatórias e insurgentes avançarem na catalisação e unificação de lutas democráticas e emancipatórias. As análises das suas formas renovadas de lutas, suas opções táticas e estratégicas, as disputas por maior justiça social e ambiental avançaram sobremaneira nas últimas décadas.

A canalização das energias de insatisfação e de inconformismo se expressa em formatos variados, em contra-re-ações protetoras da sociedade atingida, sem direitos e sem voz, e lógicas organizativas portadoras de ações e reações de resistência e de encadeamentos de vetos, que são passíveis ou não de se constituírem em coalizões insurgentes e alternativas. A potência das relações de força das múltiplas formas de indignação, mobilização. Inconformados, destituídos de direitos, de fala e de meios de consumo coletivo travam no dia-a-dia lutas contra opressões de toda 
espécie, trazendo a nova energia da insatisfação para variados espaços de contestação.

Alguma noção mundana de compartilhamento de experiências particulares vividas, de cotidianidade, de sentidos e sentimentos de referência, pertencimento, identidade ou significante, um ponto singular no espaço, também está presente em quase todas as definições de lugar que ainda apresentam algum diálogo com a reprodução social das práticas da vida cotidiana e a interação humana.

São lutas por justiça socioespacial, conflitos promotores de contra-re -ações protetoras da sociedade atingida e lógicas organizativas portadoras de ações e reações de resistência (em múltiplas formas) e de encadeamentos de vetos, que são passíveis ou não de se constituírem em coalizões insurgentes e alternativas.

\section{(In)conclusões}

Neste ensaio, mesmo quando não explicitado, estamos colocando ênfase na escala regional. A escala regional pode melhor demarcar o campo das lutas sociais, dar concretude a bandeiras, clivagens e orientações de lutas e ações políticas, delimitar e criar a ancoragem identitária, a partir da qual se pode lograr erguer um contencioso em relação a imposições de decisões (por vezes ameaçadoras) provenientes de outras regiões, na mesma ou em outras escalas.

O estudo das decisões em uma escala regional, com repercussões e manifestações em uma intricada cadeia de ações e reações em outras escalas, requer uma abordagem metodológica estrutural-conjuntural e relacional. Uma escala pode ser definida e determinada e qualificada apenas em relação às outras. Parte das dinâmicas e lógicas escalares repousa nos nexos, acionamentos e coerências interescalares, nas interregionalidades e interdependências. Nesse sentido, as decisões ao longo da divisão inter-regional do trabalho, o específico ambiente e o contexto histórico regionais, suas particulares relações e coalizões de poder e suas estratégias político-reprodutivas devem ser o objeto primordial da pesquisa regional.

Certas lutas sociais podem se manifestar na forma de narrativas escalares regionais democrático-populares. Assim, é decisivo analisar espaços-tempos variados nas escalas de observação e ação: mesorregional, microrregional, da cidade, do bairro, da comunidade etc. Tais espaços tempos podem sustentar uma cadeia potente de contrarreações, que, por 
sua vez, podem lograr alargar, pulverizar e democratizar os mecanismos de decisão. Eles podem engendrar mecanismos mais descentralizados e democráticos de decisão, potencializando ou antepondo cadeias de reação a decisões hegemônicas antipopulares e antidemocráticas.

A escala do lugar, fundante para se analisar as práticas espaciais de sujeitos sociopolíticos que tem a intenção de objetivar e concretizar seus projetos singulares de reprodução da vida, requer análises apuradas. $\mathrm{O}$ ambiente construído e suas estruturas espaciais envolvem os projetos individuais do terreno da vida cotidiana. Mas, o mesmo ambiente construído e suas estruturas espaciais também são envolvidos e elaborados pelos projetos da vida cotidiana. No nível de análise fundamental da imediaticidade, ou seja, da teia fina do tecido social, é crucial se atentar para as práticas espaciais no contexto da esfera essencial imediata e pragmática da reprodução da vida cotidiana e intrínseca a cada um(a). Assim, o lugar é o lócus do pragmatismo, da reprodução imediata, da convivência, do vivenciado, do circunstanciado e das espacialidades e temporalidades específicas, porção espacial das práticas da vida cotidiana e manifestação menos mediada, portanto mais imediata, das relações sociais, logo, espaço do acontecer e das singularidades. Nesta escala espacial, capacidades de respostas mais imediatas e conjunturais a situações reais e particulares são formuladas e implementadas.

Em suma, o aparato crítico-conceitual a ser construído e acionado requer melhor análise e qualificação das novas e das velhas formas de disputa em torno do ambiente construído, colocando as questões do poder e dos processos decisórios dos agentes dominantes (Estado e grande empresa) no centro da análise e da ação, reposicionando as cadeias de reação a decisões hegemônicas, que deveriam ser contrapostas e colocadas em xeque.

Para pensar as espacialidades e as temporalidades diferenciais dos processos sociais regionalizados, sobretudo, em conjuntura de aguda crise disruptiva, é preciso examinar o encadeamento concreto das decisões em cada território sob análise. E pensar as interregionalidades, interescalaridades e os interesses e as contradições inter-classes, em presença, in loco, ao longo dos tempos e nos variados espaços. E procurar vencer a ideia de decisões racionais individualizadas, de forma a construir e coordenar decisões ousadas, que verdadeiramente possam enfrentar as multidimensionais destituições, desigualdades e injustiças e promovam uma outra produção social do espaço. 


\section{Referências Bibliográficas}

ALCOUFFE, Alain (2009). Furtado, o Brasil e os economistas franceses: influências cruzadas. In: COELHO, Francisco S. e GRANZIERA, Rui G. Celso Furtado e a Formação Econômica do Brasil. São Paulo, Atlas/ OEB, pp. 34-46.

BERNDT, C.; PECK, J.; RANTISI, N. (eds.) (2020). Market/place: exploring spaces of exchange. Newcastle upon Tyne: Agenda Publishing, 2020.

BOURDIEU, Pierre (2005). O singular e o plural. In: ENCREVÉ, Pierre; LAGRAVE, Rose-Marie (coord.). Trabalhar com Bourdieu. Rio de Janeiro, Bertrand Brasil.

CAHILL, Damien et al. (eds.) (2019). The Sage Handbook of Neoliberalism. Los Angeles, Sage.

MONTAÑO, Carlos e DURIGUETTO, Maria Lúcia (2013). Estado, classe e movimento social. São Paulo, Cortez.

FURTADO, Celso (1982). Nova Dependência. São Paulo, Paz e Terra.

GARCÍA, Ariel y ROFMAN, Alejandro (2013). Poder y espacio. Hacia una revisión teórica de la cuestión regional en Argentina. Revista Problemas del Desarrollo, 175 (44): 101-124.

MASSEY, Doreen and RUSTIN, Michael (2015). Displacing neoliberalism. In: Hall, Stuart, Massey Doreen and Rustin Michael (2015). After neoliberalism: Kilburn Manifesto London: Lawrence \& Wishart.

HALL, Stuart and MASSEY, Doreen (2010). Interpreting the crisis, Soundings, (44): 57-71.

JESSOP Bob (2019) Authoritarian neoliberalism: periodization and critique South Atlantic Quarterly. 118(2): 343-361.

JESSOP Bob and KNIO Karim (2019). The pedagogy of economic, political and social crises: dynamics, construals and lessons. London, Routledge.

JESSOP, Bob (2007). Estratégias de acumulação, formas estatais e projetos hegemônicos. Ideias, Campinas, 14(1-2): 101-135. 
MARKUSEN, Ann (2005). Mudança econômica regional segundo o enfoque centrado no ator. In: DINIZ, Clélio Campolina; LEMOS, Mauro Borges (orgs.). Economia e território. Belo Horizonte, Editora UFMG.

MORAIS, Antônio Carlos R. (2002). Ideologias geográficas: espaço, cultura e política no Brasil. São Paulo, Hucitec.

NASH, Kate. Post-democracy, politics and philosophy: An interview with Jacques Rancière. Angelaki: Journal of the Theoretical Humanities, s.l., v. 1, n. 3, p. 171-178, 1996.

OLIVEIRA, Francisco de (2001). Pensar com radicalidade e com especificidade. Lua Nova, São Paulo, (54): 89-95.

POLANYI, Karl [1944]. A grande transformação: as origens da nossa época. Rio de Janeiro: Campus, 1980.

RANCIÈRE, Jacques (1996). Post-democracy, politics and philosophy: an interview with Jacques Rancière. Angelaki 1(3):171-78.

ROFMAN, Alejandro B. (1974). Dependencia, estructura de poder y formación regional en América Latina. Buenos Aires, Siglo Veintiuno.

SARDAR, Ziauddin (2010). Welcome to postnormal times. Futures, (42): 435-444.

SERENI, Emilio (1973). La categoria de formación económico-social. In: LUPORINI, Cesare et al. El concepto de formación económico-social. Buenos Aires, Siglo Veintiuno.

SOUSA SANTOS, Boaventura (2020). La cruel pedagogía do virus. Ciudad Autónoma de Buenos Aires, CLACSO.

SUNKEL, Oswaldo e PAZ, Otávio (1971). Teoria do desenvolvimento econômico. São Paulo, Difel.

WEBER [1922]. Economia e sociedade. Brasília, Editora da UnB, 1994. 